\title{
Photocatalytic Activity of Titania Nanotube Coatings Enriched With Nanohydroxyapatite
}

\author{
Aleksandra Radtke*1,2 \\ ${ }^{1}$ Faculty of Chemistry, Nicolaus Coprnicus University in Torun, Poland \\ ${ }^{2}$ Nano-implant Ltd, Torun, Poland
}

*Corresponding author: Aleksandra Radtke, Faculty of Chemistry, Nicolaus Coprnicus University in Torun, Poland

\begin{tabular}{|c|c|}
\hline ARTICLE INFO & ABSTRACT \\
\hline $\begin{array}{l}\text { Received: February 24, } 2019 \\
\text { Published: March 05, } 2019\end{array}$ & $\begin{array}{l}\text { Photocatalytic activity of titania nanotube coatings (TNT) enriched with } \\
\text { nanohydroxyapatite (HA) has been studied on the basis of UV-induced degradation of }\end{array}$ \\
\hline $\begin{array}{l}\text { Citation: Aleksandra Radtke. Photo- } \\
\text { catalytic Activity of Titania Nanotube } \\
\text { Coatings Enriched With Nanohy- } \\
\text { Aroxyapatite. Biomed J Sci \& Tech Res }\end{array}$ & $\begin{array}{l}\text { morphology on their photocatalytic properties has been determined. The results of my works } \\
\text { proved that in all studied TNT/HA samples hydroxyapatite increased the photocatalytic } \\
\text { activity of titania nanoporous coatings. Obtained results pointed out the synergistic activity } \\
\text { of HA nanocrystals deposited on the surface of titania nanotubular systems. }\end{array}$ \\
\hline
\end{tabular}
15(3)-2019. BJSTR. MS.ID.002711.
Keywords: Titania Nanotubes; Hydroxyapatite; Photocatalytic Activity; Methylene Blue Photodegradation; Morphology

\section{Introduction}

Hydroxyapatite (HA) has the similar chemical composition as bone tissues mineral phase and therefore it attracts the interest of the scientific community in the medicine, material science, tissue engineering and implantology [1-4]. In my earlier investigations I used it to enrich the nanotube coating (TNT) on implants made of titanium alloy [5]. The inserting of $\mathrm{TiO}_{2}$ inner layer between very thin HA coating and Ti6Al4V substrate, the adhesion strength increase of the coating surface was possible [5,6]. Moreover, the addition of $\mathrm{TiO}_{2}$ inner layer should prevent the corrosion of the Ti alloy substrate and lead to achieve a surface free of cracks. The use of HA in the TNT/HA system allows also on the production of materials, which have a large surface area and high adsorption ability. In this application HA plays the role of a transparent or semi-transparent material to allow UV and visible radiation to pass through it and reach the true photocatalyst, which is $\mathrm{TiO}_{2}$ [7]. Biological and chemical molecules adsorption on the HA surface generally depends on its crystallite size and morphology of particles or coatings, which are in turn dependent on synthesis methods. Nonami et al. [8] soaked $\mathrm{TiO}_{2}$ powder in a simulated physiological solution containing phosphate ions for $1 \mathrm{~h}$ at $37^{\circ} \mathrm{C}$. The $0.7 \mu \mathrm{m}$ apatite film, consisting of crystals with plate-like shape, has formed on the approximately $0.3 \mu \mathrm{m}$ thick $\mathrm{TiO}_{2}$ layer and in this form, it could adsorb contaminants without exposure to light. Then - the contaminants were decomposed by $\mathrm{TiO}_{2}$ photocatalyst on exposure to light. Such photocatalytic $\mathrm{TiO}_{2} / \mathrm{HA}$ composites can be used to the air purification or play the role of the antimicrobial and antifungal coating with HA absorber. A facile two-step approach, which involves sol-gel process and calcination let to obtain $\mathrm{Ag}-\mathrm{TiO}_{2} / \mathrm{HA} / \mathrm{Al}_{2} \mathrm{O}_{3}$ bioceramic composite membrane was reported by $\mathrm{Ma}$ et al. [9]. In this composite membrane, HA component acted as a highly efficient bacterial adsorbent, while Ag-TiO 2 provided powerful photocatalytic activity Escherichia coli. $\mathrm{TiO}_{2}$ /HA composite with mosaic structure was fabricated by Xie et al. [10] via a facile route without any structure-directing agent. Their studies results proved that increased photocatalytic activity of the composite resulted from the combination of adsorption capacity of HA and the high photocatalytic activity of $\mathrm{TiO}_{2}$ Liu et al. [11] synthesized HA-modified $\mathrm{N}-\mathrm{TiO}_{2}$ composite using by wetchemical method and evaluated its photocatalytic activity by the decomposition of gaseous acetone under visible-light irradiation.

The results of these investigations revealed that the best photocatalytic activity was found for the $10 \%-\mathrm{HA}-\mathrm{N}-\mathrm{TiO}_{2}$ sample. This activity may arise from the synergism of adsorption ability of HA and titania photocatalytic activity manifested in generation 
of oxygen-reactive species, their diffusion and reaction with the acetone molecules located on the HA. Beside the role as an adsorption material in the photocatalytic $\mathrm{TiO}_{2} / \mathrm{HA}$ composites, some recent studies showed that hydroxyapatite promotes photocatalytic degradation, supporting the real photocatalyst [7]. The activity of $\mathrm{HA}$ is assigned to the generation of active superoxide anion radicals $\left(\mathrm{O}_{2}{ }^{-}\right)$due to a change, which has place in the electronic state of the surface $\mathrm{PO}_{4}^{3-}$ group under UV irradiation [12]. Mohamed et al. [13] studied photocatalytic activity of $\mathrm{Pd}^{-\mathrm{TiO}_{2}}$-HA composites, using visible light-induced photocatalytic removal of cyanide. Authors showed that vacancies formed on the surface of the excited $\mathrm{PO}_{4}{ }^{3}$ group under visible light, let to the formation of $\mathrm{O}_{2}$, which are able to attack the organic molecules adsorbed on HA. Zhang et al. [14] pointed out the influence of internal polarization of HA (which promotes the separation of photogenerated electrons and holes) on increasing photocatalytic performance of $\mathrm{TiO}_{2}$ nanoparticles, which were supported on electrically polarized HA films.

In this short article I present the results of my works on photocatalytic activity TNT/HA nanocomposites possessing optimal (in terms of adequate adhesion) thickness of hydroxyapatite obtained with the use of atomic layer deposition method. The presented results are the supplement of current knowledge on the impact of hydroxyapatite on the photocatalytic properties of composite systems based on $\mathrm{TiO}_{2}$ and $\mathrm{HA}$. The possible biomedical applications of the TNT/HA system have been discussed in my earlier work [5]. The proven photocatalytic activity of these systems, which is presented here, will be their additional advantage, which can be used for example in the processes of surface sterilization of implants (possessing a surface layer in the form of a TNT/HA nanocomposite), using UV radiation.

\section{Materials and Methods}

\section{Anodic Oxidation of Ti6Al4V Substrates and Preparation of Ti6Al4V/TNT/HA Coatings}

TNT system on the surface of Ti6Al4V substrates were fabricated with the use of the electrochemical anodic oxidation method, applying previously described conditions (Ti6Al4V, grade 5 foil, $99.7 \%$ purity, $0.20 \mathrm{~mm}$ thick, Strem Chemicals, Inc. (Bischheim, France), $7 \mathrm{~mm} \times 70 \mathrm{~mm}$ pieces) $[15,16]$. The anodization time was $20 \mathrm{~min}$, and the process was carried out at potentials: $5 \mathrm{~V}$ (TNT5), $10 \mathrm{~V}$ (TNT10), $12 \mathrm{~V}$ (TNT10), $15 \mathrm{~V}$ (TNT15), $18 \mathrm{~V}$ (TNT18), and $30 \mathrm{~V}$ (TNT30). The structure of the produced TiO2 nanotube layers was studied using Raman spectroscopy (RamanMicro 200 PerkinElmer (PerkinElmer Inc., Waltham, USA) $(\mathrm{l}=785 \mathrm{~nm})$ ) and diffuse reflectance infrared Fourier transform spectroscopy (DRIFT, Spectrum2000, PerkinElmer Inc., Waltham, USA). The morphology of the coatings was examined using a Quanta scanning electron microscope with field emission (SEM, Quanta 3D FEG, Huston USA). Hydroxyapatite was fabricated on the surface of Ti6Al4V/TNT substrates by the two-stage procedure: a) deposition of $\mathrm{CaCO}_{3}$ thin film using the ALD method (100 cycles) and

b) conversion of the $\mathrm{CaCO}_{3}$ film into crystalline hydroxyapatite by a reaction with aqueous $\left(\mathrm{NH}_{4}\right)_{2} \mathrm{HPO}_{4}$ - detailed procedure is given in $[5,17,18]$. The morphology of the fabricated coatings (both stages) was studied using a Hitachi S-4800 field emission scanning electron microscopy FE-SEM (Hitachi HighTechnologies Corporation, Tokyo, Japan). Samples were sputter coated with $2 \mathrm{~nm} \mathrm{Au} / \mathrm{Pd}$ prior to imaging, to enhance image quality. Grazing incidence X-ray diffraction (GIXRD) studies were done using an X-ray diffractometer PANalytical X'Pert Pro MPD (PANalytical B.V., Almelo, Netherlands); CuK $\alpha$ radiation and an incident angle of $1^{\circ}$.

\section{Photocatalytic Activity Test}

The photocatalytic activity of the produced titania coatings enriched with thin hydroxyapatite film, as well as pure ones, were estimated using the most used procedure in the literature, i.e. methylene blue ( $\mathrm{MB}, \mathrm{c}=0.01 \mathrm{mM}, 3 \mathrm{~cm}^{3}$ ) photodegradation. Additionally, the same measurements have been made for Ti6Al4V and Ti6Al4V/HA. In all cases, I was waiting 30 minutes for the adsorption equilibria (in the darkness), after the samples of the porous materials were immersed in the aqueous $10^{-5}$ methylene blue solution. Then, they were illuminated by UV radiation $(18 \mathrm{~W}$, range of 340-410 $\mathrm{nm}$ with maximum at $365 \mathrm{~nm}$, UV irradiance on the film surface was measured to be $0.8 \mathrm{~mW} / \mathrm{cm}^{2}$ ). The changes in $\mathrm{MB}$ concentration (absorbance measured at $\lambda=664 \mathrm{~nm}, \varepsilon=$ $95000 \mathrm{~cm}^{-1} \mathrm{M}^{-1}$ ) were registered every $24 \mathrm{~h}$ for seven days by spectrophotometric analysis (Metertech SP-830 PLUS). All analysed samples had dimensions of $7 \mathrm{~mm} \times 7 \mathrm{~mm}$.

\section{Results and Discussion}

Using the anodic oxidation of Ti6Al4V samples in $0.3 \mathrm{wt} \%$ aqueous HF solution it was possible to obtain nanotubular coatings (TNT), in which the nanotube diameters were in the range 18 - 140 nm depending on the applied potential (Figure 1). Their enrichment with HA gave composite coatings, in which hydroxyapatite crystals evenly cover the nanotube coating, but do not form a continuous layer. Analysis of SEM images of TNT/HA samples revealed that the morphology of the analyzed systems differs in density of HA nanocrystals on the surface of nanotubes. However, the nanotube architecture of layer located under HA nanocrystals, is clearly visible (Figure 2). The Ti6Al4V/HA sample (HA deposited on a pure titanium alloy) is completely different from all tested systems. The SEM image shows, that the density of the hydroxyapatite nanocrystals on the titanium alloy sample is the lowest (Figure 2). According to received results, the change of the TNT coating surface nanoarchitecture (and also tubes diameter), as it has place in the case of titania dioxide nanotubes produced at different potentials, influences on the distribution density of produced hydroxyapatite nanocrystals. As the structure of the analyzed systems has been 
described in detail [5] and the applied synthesis procedure has not been changed - here I do not present structural studies, however I would like to point out that the titanium dioxide nanotubes obtained by anodic oxidation method of the titanium alloy are amorphous and the hydroxyapatite is in a crystalline form.
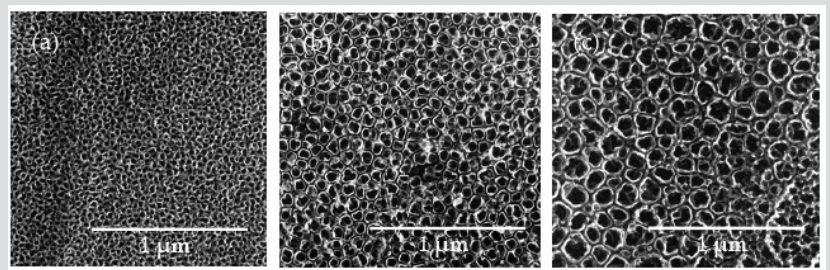

Figure 1: SEM images examples of TNT: (a) TNT5, (b) TNT12, (c) TNT30.

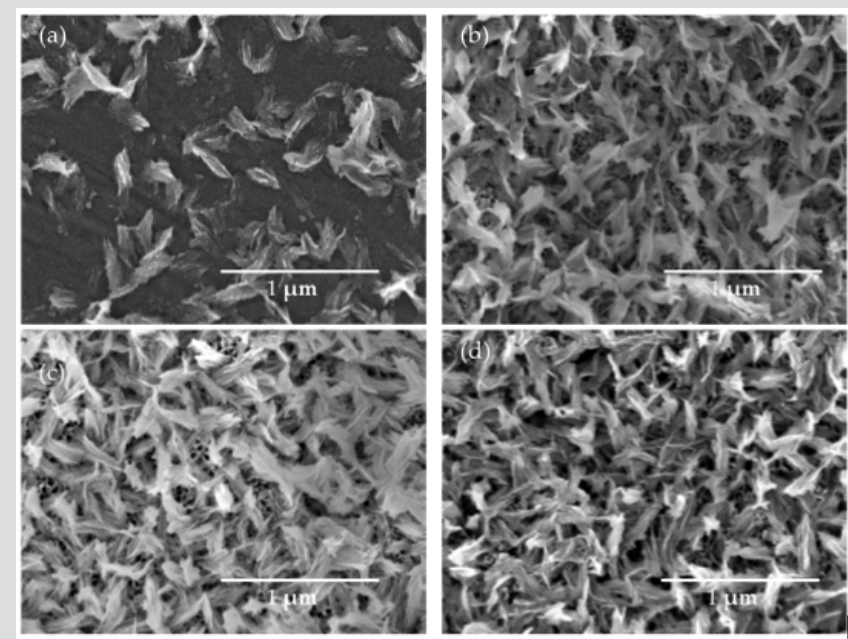

Figure 2: SEM images of (a) Ti6Al4V/HA, (b) TNT5/HA, (c) TNT12/HA, (d) TNT30/HA.
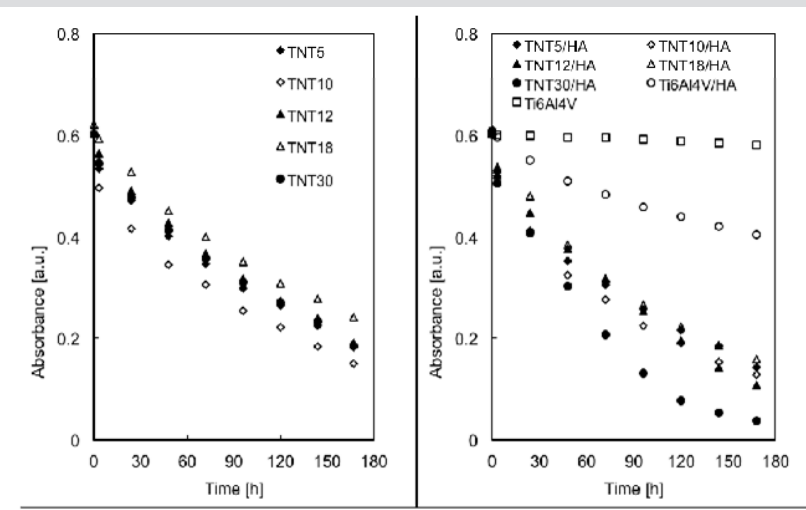

Figure 3: Absorbance-time data for methylene blue photodegradation for titania nanotubes (TNT), titania nanotubes enriched with HA (TNT/HA), titanium alloy Ti6Al4V, and titanium alloy enriched with HA (Ti6Al4V/ HA).

The results referring to photodegradation processes measurements of methylene blue under the UV light irradiation are presented in Figures 3-5. The photocatalytic activity of pure TNT layers
(Figure 3) was compared with the results received titania nanotube coatings enriched with hydroxyapatite (TNT/HA) as the photocatalysts (Figure 3). Additional comparison was made for pure titanium alloy, non-modified (Ti6Al4V) and titanium alloy enriched with HA (Ti6Al4V/HA); (Figure 3). Due to the fact that absorbance-time dependency for methylene blue photodegradation is neither linear nor typically exponential in the whole studied range of time, I have decided to the estimate the medium reaction rate of the MB photodegradation, whose measure is the rate constant $k_{168}$ (Figure 4), and degree of MB degradation - $a_{168}$ (Figure 5). In both cases, the time taken to calculations was equal to 168 hours. Analysis of data presented in Figures 3 \& 4 exhibits, that for every studied pair, i.e. TNT and TNT/HA, the methylene blue photodegradation is faster, when titania nanotube layers enriched with hydroxyapatite nanocrystal are used as photocatalysts.

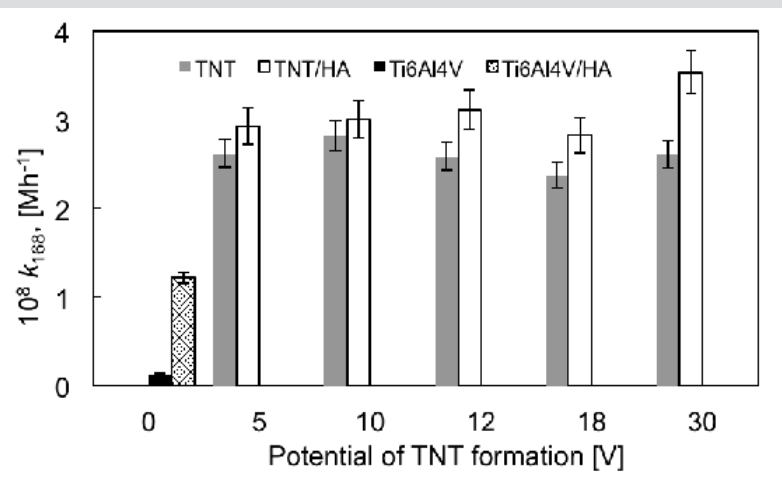

Figure 4: Values of medium rate of methylene blue degradation in the presence of Ti6Al4V/HA, TNT, and TNT/HA.

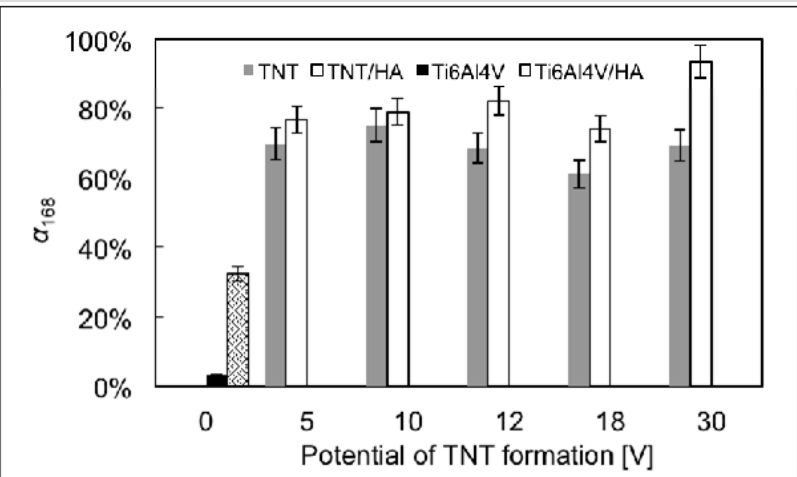

Figure 5: Degree of methylene blue degradation in the presence of Ti6Al4V, Ti6Al4V/TNT/HA, TNT, and TNT/ HA.

The same dependency is visible for Ti6Al4V and Ti6Al4V/ HA samples - also in this case the enrichment of the titanium alloy surface with HA nanocrystals increases its photocatalytic activity. The degree of methylene blue degradation, induced by UV irradiation, increased more than eight times for Ti6Al4V/ HA system in comparison to pure titanium alloy substrate. The 
studies of Ti6Al4V and Ti6Al4V/HA samples confirmed the clear photocatalytic activity of HA nanocrystals, which is in agreement with literature data [19]. The weak, but noticed, photocatalytic activity of Ti6Al4V sample can be attributed to the formation on its surface the natural titanium oxide passivation layer, which in fact is responsible for photocatalytic activity [20]. Among studied systems TNT/HA, the highest photocatalytic activity exhibited the TNT30/HA sample, i.e. the system formed by TNT layer (composed of nanotubes of biggest diameter, c.a. $140 \mathrm{~nm}$ ) not fully covered by HA nanocrystals. In this case, the larger nanotubes diameter allows to get analysed solution into tubular interior, and thus into the interior of the layer, increasing the efficiency of MB decomposition. For the rest of TNT/HA samples the activity is almost on the same level.

The increase of the medium reaction rate of MB degradation processes for TNT/HA systems in comparison to TNT systems is in the range $6.70 \%$ (for TNT10/HA) - 35.5\% (for TNT30/HA), and the degree of MB degradation increases by $3.90 \%$ (for TNT10/HA and TNT systems) to $24.4 \%$ (for TNT30/HA and TNT30 systems). Such a significant increase (especially in the case of TNT30/HA sample) in photocatalytic activity of TNT/HA systems can be attributed to the double role played by hydroxyapatite nanocrystals covered the surface of the TNT layer, i.e. as an adsorption material on the composites surface, allowing UV radiation to pass through it and reach $\mathrm{TiO}_{2}$, as well as real photocatalyst, which generates active superoxide anion radicals $\left(\mathrm{O}_{2}^{-}\right)$in the electronic state of the surface $\mathrm{PO}_{4}{ }^{3-}$ group under UV irradiation $[7,12,13]$.

\section{Conclusion}

In all studied samples the same relationship was noticed, i.e. the clear increase of photocatalytic activity of TNT coatings covered by HA nanocrystals, in MB degradation. This can be explained by a synergistic acting of HA nanocrystals deposited on the surface of titania nanotubular systems. In this case, hydroxyapatite, which possess high adsorption ability, act as:

a) Material allowing UV radiation to pass through it and reach the true photocatalyst, which is $\mathrm{TiO}_{2}$ nanotube coating, as well as

b) Real photocatalyst, which generates active entities, e.g. superoxide anion radicals $\left(\mathrm{O}_{2}{ }^{--}\right)$.

\section{References}

1. Li SH, De Wijn JR, Layrolle P, De Groot K (2002) Synthesis of macroporous hydroxyapatite scaffolds for bone tissue engineering. J Biomed Mater Res 61: 109-120.

2. Flautre B, Descamps M, Delecourt C, Blary MC, Hardouin P (2001) Porous HA ceramic for bone replacement: role of the pores and interconnections-experimental study in the rabbit. J Mater Sci Mater Med 12: 679-682.

3. Wei G, Ma PX (2004) Structure and properties of nano-hydroxyapatite/ polymer composite scaffolds for bone tissue engineering. Biomaterials 25(19): 4749-4757.
4. Kalita SJ, Bhardwaj A, Bhatt HA (2007) Nanocrystalline calcium phosphate ceramics in biomedical engineering. Materials Science and Engineering 27(3): 441-449.

5. Radtke A, Ehlert M, Jędrzejewski T, Sadowska B, Więckowska Szakiel M, et al. (2019) Titania nanotubes/hydroxyapatite nanocomposites produced with the use of the Atomic Layer Deposition technique: estimation of bioactivity and nanomechanical properties. Nanomaterials 9: 123.

6. Chen D, Jordan EH, Gell M, Wei M (2008) Apatite formation on alkalinetreated dense $\mathrm{TiO}_{2}$ coatings deposited using the solution precursor plasma spray process. Acta Biomaterialia 4: 553-559.

7. Thi Truc LN, Hong S, No K (2018) Evaluation of the Role of Hydroxyapatite in $\mathrm{TiO}_{2} /$ Hydroxyapatite Photocatalytic Materials, In book: Photocatalysts: Applications and Attributes.

8. Nonami T, Hase H, Funakoshi K (2004) Apatite-coated titanium dioxide photocatalyst for air purification. Catalysis Today 96: 113-118.

9. Ma N, Fan X, Quan X, Zhang Y (2003) Ag-TiO $/ 4 \mathrm{HAp} / \mathrm{Al}_{2} \mathrm{O}_{3}$ bioceramic composite membrane: Fabrication, characterization and bactericidal activity. Journal of Membrane Science 336: 109-117.

10. Xie J, Meng X, Zhou Z, Li P, Yao L, et al. (2013) Preparation of titania/ hydroxyapatite $\left(\mathrm{TiO}_{2} / \mathrm{HAp}\right)$ composite photocatalyst with mosaic structure for degradation of pentachlorophenol. Materials Letters 1(10): 57-60.

11. Liu Y, Yang Q Wei JH, Xiong R, Pan CX, et al. (2011) Synthesis and photocatalytic activity of hydroxyapatite modified nitrogen-doped $\mathrm{TiO}_{2}$. Materials Chemistry and Physics 129: 654-659.

12. Reddy MP, Venugopal A, Subrahmanyam M (2007) Hydroxyapatite photocatalytic degradation of calmagite (an azo dye) in aqueous suspension. Applied Catalysis B: Environmental 69(3-4): 164-170.

13. Mohamed RM, Baeissa ES (2013) Preparation and characterisation of Pd$\mathrm{TiO}_{2}$-hydroxyapatite nanoparticles for the photocatalytic degradation of cyanide under visible light. Applied Catalysis A: General 464: 218-224.

14. Zhang X, Yates MZ (2018) Enhanced photocatalytic activity of $\mathrm{TiO}_{2}$ nanoparticles supported on electrically polarized hydroxyapatite. ACS Applied Materials \& Interfaces 10: 17232-17239.

15. Radtke A, Topolski A, Jędrzejewski T, Kozak W, Sadowska B, et al. (2017) The bioactivity and photocatalytic properties of titania nanotube coatings produced with the use of the low-potential anodization of $\mathrm{Ti}_{6} \mathrm{Al}_{4} \mathrm{~V}$ alloy surface. Nanomaterials 7(197): 1-15.

16. Radtke A, Topolski A, Jędrzejewski T, Kozak W, Sadowska B, et al. (2017) Bioactivity Studies on Titania Coatings and the Estimation of Their Usefulness in the Modification of Implant Surfaces. Nanomaterials 7: 90.

17. Avila I, Pantchev K, Holopainen J, Ritala M, Tuukkanen J, et al. (2018) Adhesion and mechanical properties of nanocrystalline hydroxyapatite coating obtained by conversion of atomic layer deposited calcium carbonate on titanium substrate. Journal of Materials Science: Materials in Medicine 29: 111.

18. Holopainen J, Kauppinen K, Mizohata K, Santala E, Mikkola E, et al. (2014) Preparation and bioactive properties of nanocrystalline hydroxyapatite thin films obtained by conversion of atomic layer deposited calcium carbonate. Biointerphases 9: 031008.

19. Piccirillo CL, Castro PM (2017) Calcium hydroxyapatite-based photocatalysts for environment remediation: Characteristics, performances and future perspectives. Journal of Environmental Management 193: 79-91.

20. Gemelli E, Camargo NHA (2007) Oxidation kinetics of commercially pure titanium. Matéria 12(3): 525-531. 


\section{ISSN: 2574-1241}

DOI: 10.26717/BJSTR.2019.15.002711

Aleksandra Radtke. Biomed J Sci \& Tech Res

(C) (i) This work is licensed under Creative

Submission Link: https://biomedres.us/submit-manuscript.php

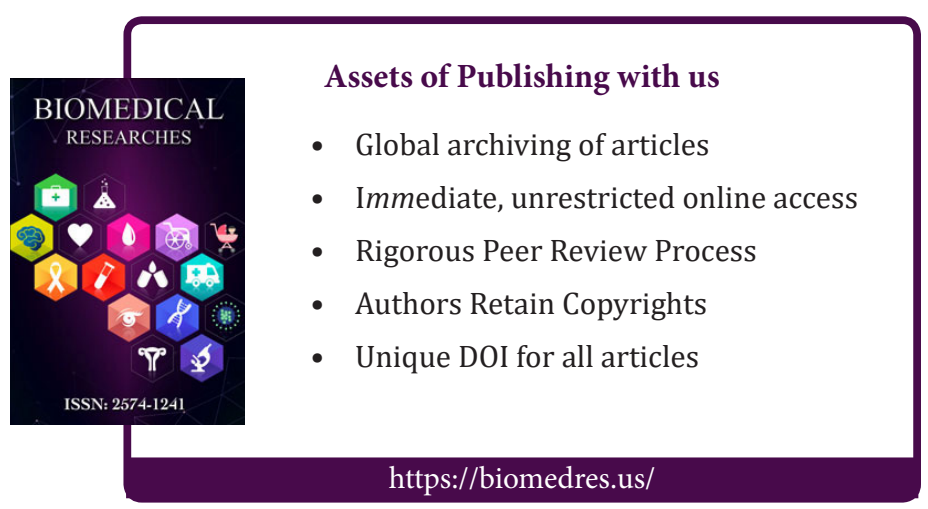

